\title{
Influence of Particulate Graphite Additions on the Shear Related Behaviour of Glass Fabric Reinforced Epoxy Composites
}

\author{
N. SAINATHAN, K. PADMANABHAN, S. SASHIDHARA, \\ R. M. V. G. K. RAO** AND KISHORE* \\ Department of Metalliurgy \\ Indian Institute of Science \\ Bangalore 560012 \\ India
}

ABSTRACT: Glass fabric reinforced composite laminates with two different epoxy formulations as matrix materials were fabricated with discretely varying additions of particwate graphite upto $6 \mathrm{wt} \%$. The influence of these additions on the shear related behaviour of the composite is reported. While the interlaminar shear strength (ILSS) of the composites with both the resin formulations and two different widths exbibited a decreasing set of walues for 2 and 4 wt \% graphite, thiose for the 6 wt \% additions indicated a trend towards cither a saturation or marginal recovery. The compression strengths for the composites Gabricated with the two rosin formulations showed opposing trends in that the specimens with the room temperature cured resin exhibited an increase upto $4 \mathrm{wt} \%$ graphite. The shear strength in compression was observed to be larger than the ILSS values of the abovesaid laminates. The transverse modulus of the composites exhibited an increase upto $4 \mathrm{wt} \%$ graphite. Scanning Electron Microscopy (SEM) was carried out on the failed specimens and the observed fracture features are reported.

\section{INTRODUCTION}

POXY RESINS ARE one of the most common class of materials used in

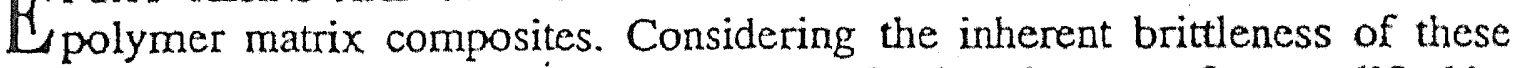
resins when compared to some of the modern plastics, they are often modified by ubber additions which improved toughness but led to deterioration in some mechanical and thermal properties. Thermoplastic additions have also been made to the epoxy resins to improve the toughness. Inorganic fillers have been successfully incorporated as second phase additions in order to essentially

Futhor to whom correspondence shruld be addressed.

"Scientist, FRP Pilot Plant, Materials Science Division, National Acrospace Laboratories, Bangalore-560017. India.

Joumal of Reinforced Plastics and Compostres, Vol. I4-May 1995 
modify the stiffness and strength of engineering plastics [1-4]. Owing to its good lubricating properties, graphite has been added in an epoxy matrix to study its effect on wear properties [5].

A perusal of the available literature points to the paucity of information on the influence of filler additions on the mechanical properties of Fibre Reinforced Plastics under various modes of shear. Incidentally, it has been recognised that the USS of laminated composites is a matrix dominated phenomenon [6]. Hence, any addition made to the matrix, is expected to affect the ILSS and other shear related properties of the composite in a beneficial or adverse manner, depending on factors like the interface, the relative hardness and brittleness, the particle size and the weight fraction of the addition, to mention some.

This work highlights the effect of graphite, an important filler material, in discretely varying quantities, on the shear related behaviour of the glass fabricl epoxy composites. Two epoxy resin formulations have been used to fabricate two different glass fabric/epoxy composites, and the influence of graphite content on their shear related behaviour has been studied.

SEM fractography was employed to characterise the fracture features and some corroborative study involving fractography with mechanical test data also reported.

$\therefore \mathrm{po}$

Mers

\section{EX́XERTMENTAL \\ ikin.t.}

Two different epoxy resin formulations viz., a room temperature cure (RTC) and a high temperature curet(HTC) were used. The epoxy resin used was diglycidyl ether of bisphenol A (DGEBA) with a trade name MY750 obtained from Hindustan Ciba Geigy-Ltd. For room temperature cure the handener used was an aliphatic amine with a trade name HY951. For the high temperature cured resin, the hardener used was an aromatic amine with a trade name HTOT2.

The reinforcement used was a 7 -mil bidirectional E-glass fabric. The glass fabric used was a four harness satin weave, with a density of $2.57 \mathrm{~g} / \mathrm{cc}$. Spectrograde graphite supplied by Graphite India Ltd., was used as the filler material with an average size of 20 microns. The particles were observed to be flaky in appearance.

The composite laminates were prepared by hand lay-up. The inner surfaces of the mould plates were first cleaned with acetone and then coated with a thin layer of wax to facilitate easy removal of the cured laminate. The hardener (12 phr) for RT cure and 27 phr for HT cure) and the required amount of graphite were added to the resin and the mixture vigorously stirred. Alternate layers of this blend and glass cloth were laid onto the mould plate by hand lay-up to a total thickness of 15 plies which by trial and error was found to be adequate to fabricate a laminate of final thickness of $3 \mathrm{~mm}$. The laminates were then compressed between the mould.plates for 24 hours. In the case of HTC laminates, they were compressed between the mould plates and then kept in an oven maintained at $125^{\circ} \mathrm{C}$ for 24 hours, after which they were cooled. To ensure uniform thickness of the laminate i.e., $3 \mathrm{~mm}$, spacers of $3 \mathrm{~mm}$ thickness were placed between the mould plates. In all, eight laminates were made, four of RTC and HTC, each with $0 \%, 2 \%, 4 \%$ 


\section{RESULTS AND DISCUSSION}

Figures 1 and 2 show the variation of ILSS with the graphite content of the laminates for the RTC and HTC laminates respectively for both specimen widths employed for the testing. From the plots it is observed that the ILSS drops noticeably for all the cases upto $4 \mathrm{wt} \%$ graphite addition and then either a saturation in the ILSS values is observed as in the case of RTC laminates or there occurs a slight recovery depending on the material tested. It seems from the plots, that on an average, the ILSS of the $5 \mathrm{~mm}$ width specimens is lower than that of the $10 \mathrm{~mm}$ width specimens.

Figures 3 and 4 show the variation of deflection at failure with graphite content for the RTC and HTC laminates respectively when tested to determine the ILSS. The plots show the deflection at failure for both the specimen widths employed. As seen from Figure 3 the deflection at failure for the RTC laminates of either width, shows a steady rise upto 4 wt $\%$ graphite and then decreases. The deflection at failure for the $5 \mathrm{~mm}$. width specimen is observed to be smaller than that of the $10 \mathrm{~mm}$ width specimens for the range of graphite additions tried in this investigation. It is interesting to note that this difference seems to be rather inriform for all the graphite additions employed in this study.

rTap!

As seen from Figure 4, the deflection at failure observed in the caserofrHTC composites shows a complete reversal of trend from that observed in the icase of RTC composites. Here, the deflection at failure decreases gradually upto is wt $\%$ graphite and then shows a steady rise. Here again the $5 \mathrm{~mm}$ width specimens showed a lower deflection than the $10 \mathrm{~mm}$ width specimens over the range of graphite additions as emphasized earlier.

Figure 5 shows the variation of the transverse modulus with graphite content for the RTC and HTC laminates. The RTC laminates show an increase in the transverse modulus reaching a peak in the range 2-4 wt \% graphite after which it decreases. The HTC laminates show a steady increase in the transverse modulus upto 4 wt \% graphite after which the decrement is less rapid.

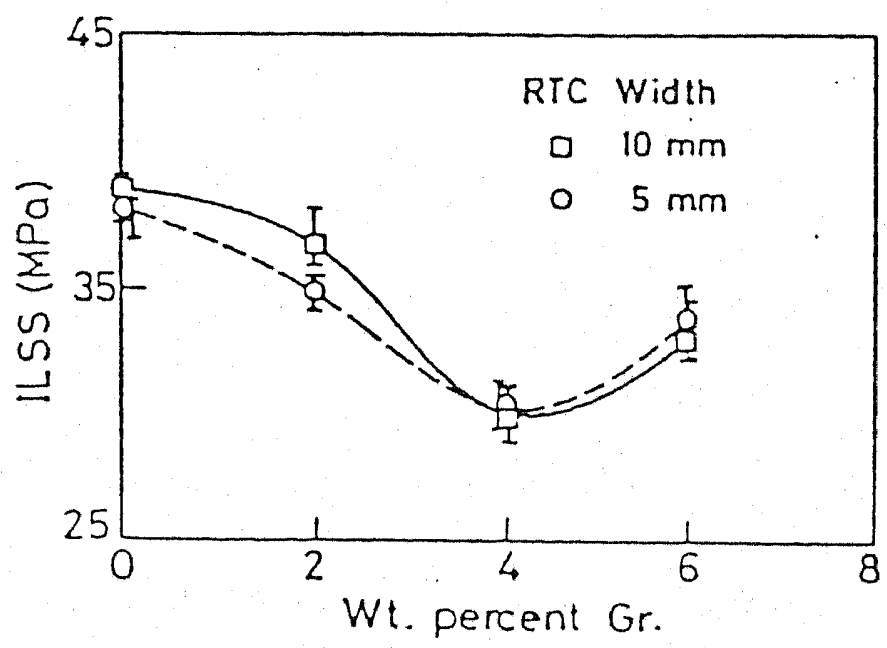

Figure 1. ILSS of room temperature cured composite laminate with varying graphite content. 


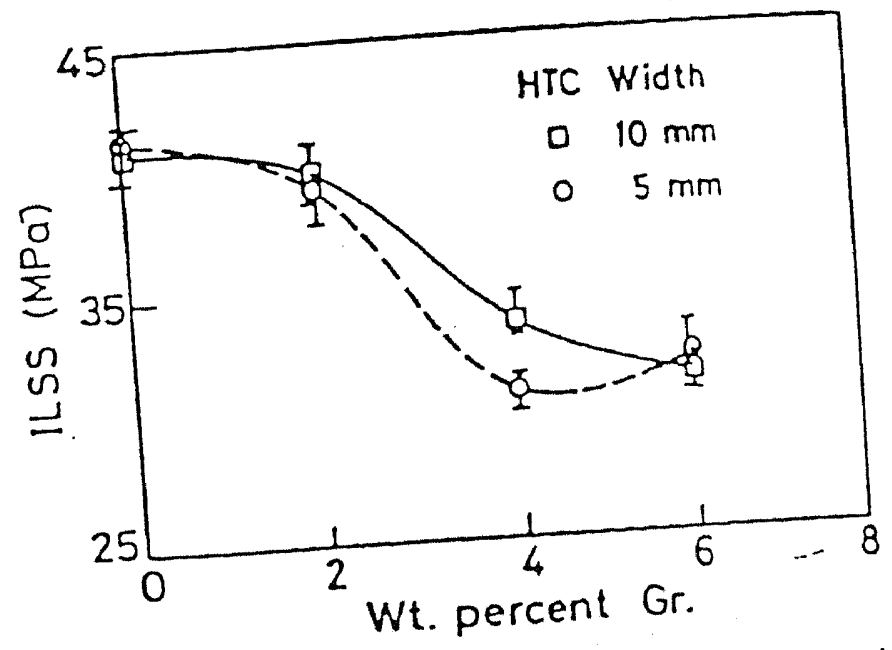

Figure 2. ILSS of high temperature cured composite laminate with varying graphite content.

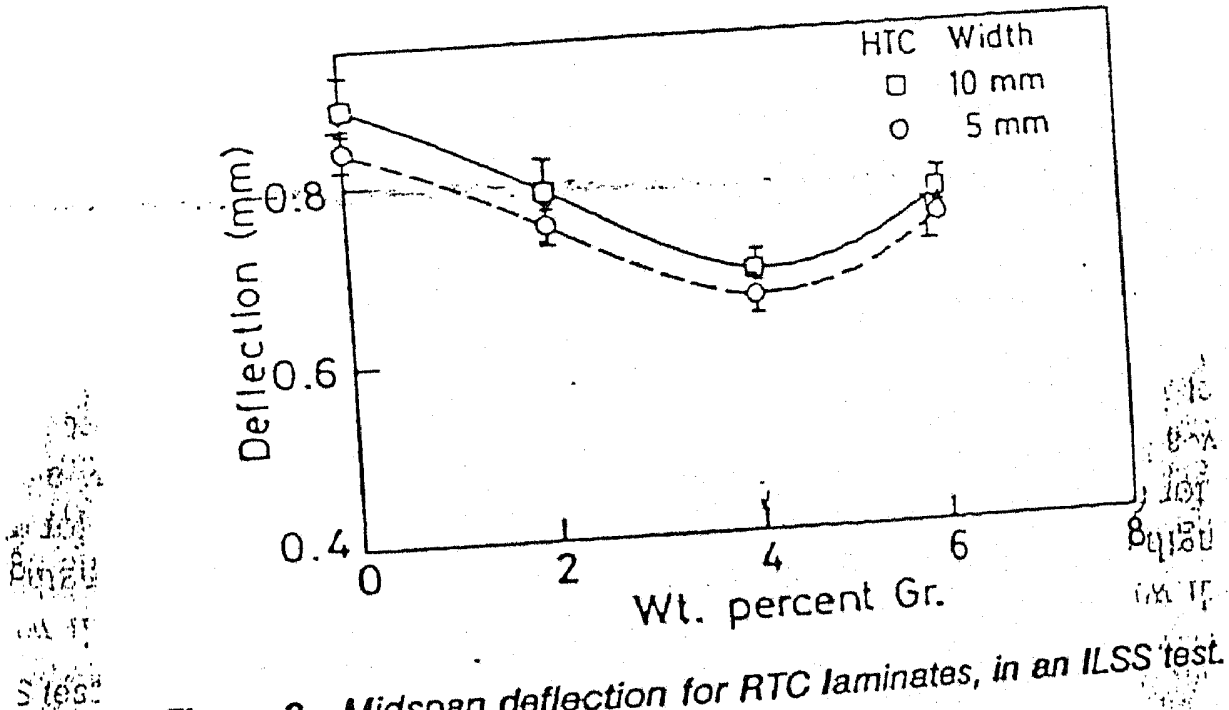

Figure 3. Midspan deflection for RTC laminates, in an thSS

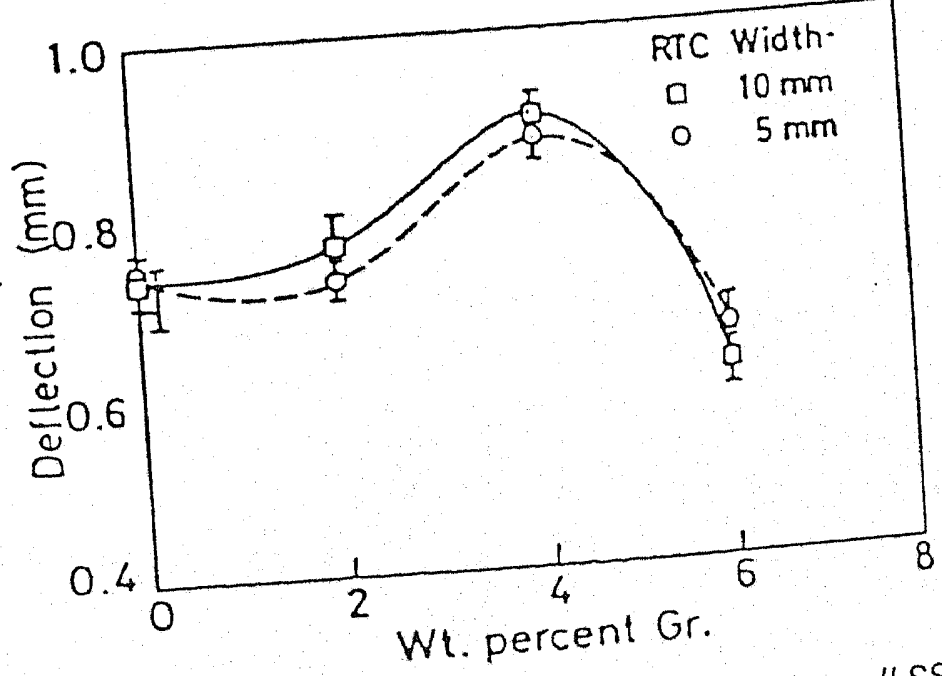

Figure 4. Midspan deflection for HTC laminates, in an ILSS test. 


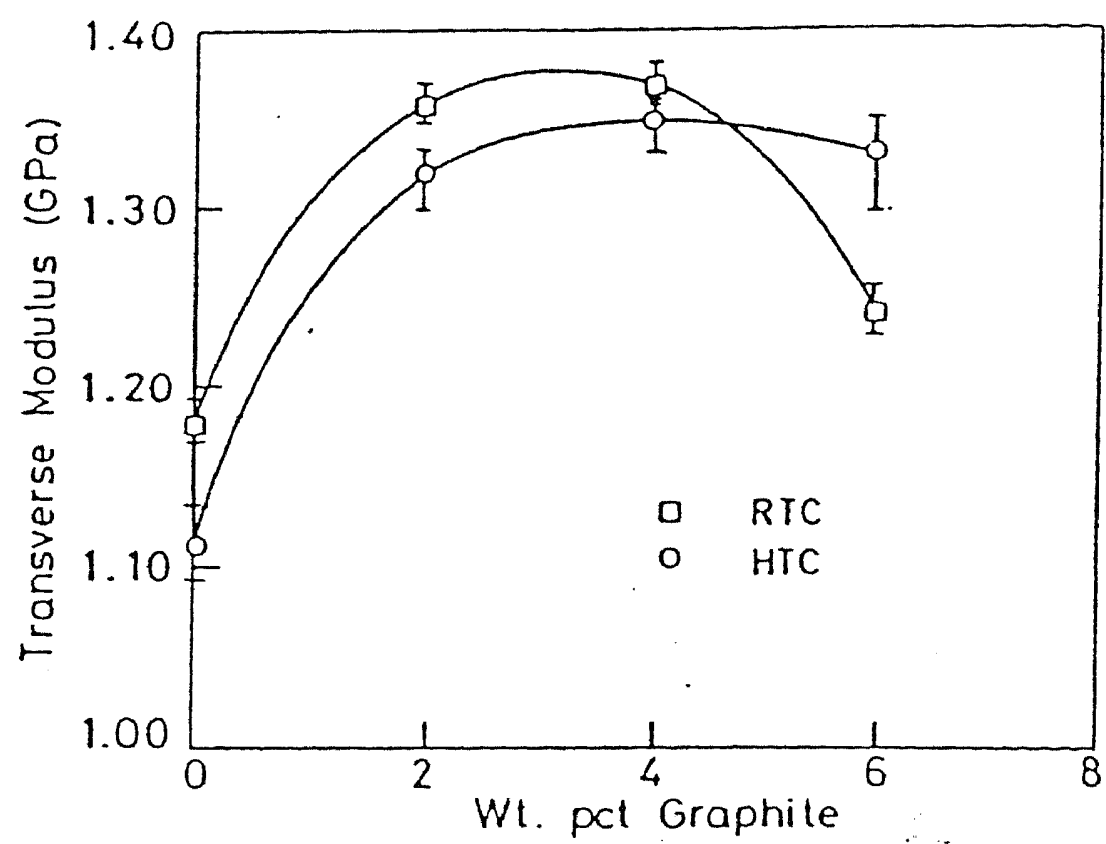

Figure 5. Transverse modulus in terision for RTC and HTC laminates.

Figure 6 shows the variation of compression strength with graphite additions 6) for the RTC and HTC Taminates. The compressive strength of the RTC laminates shows an increase upto 4 wt \% graphite and then a drop for 6 wt \% graphite, while the compressive strength of the HTC laminates show a decrease upto 4 wt\% graphite followed by a substantial increase. This aspect is discussed later.

Figure 7 shows the variation of compressive strain at failure with graphite additions for the RTC and HTC laminates. The compressive strain at failure for the RTC laminates shows a steep increase upto 4 wt \% graphite after which it decreases while the same at failure for the HTC laminate shows a slight fall upto $4 \mathrm{wt} \%$ graphite and then a small increase occurs for $6 \mathrm{wt} \%$ graphite. By comparing the compressive strain at failure and deflection at failure for ILSS it is seen that the trends observed by the RTC and HTC laminates are identical.

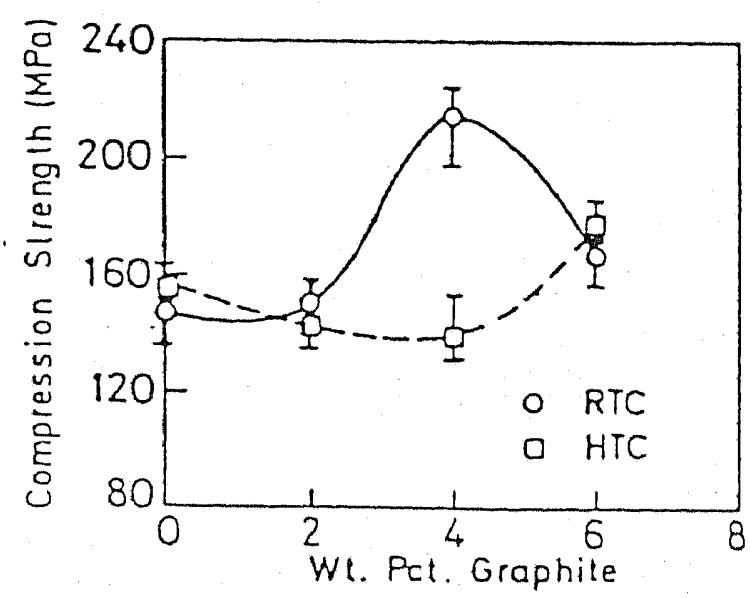

Flgure 6. Compression strength vs, graphite content for RTC and HTC laminates. 


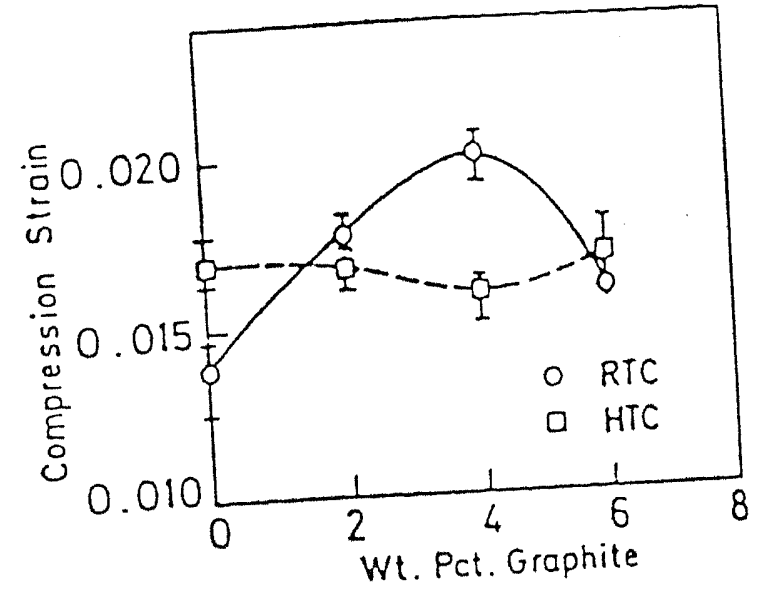

Flgure 7. Compression strain vs. graphite content for RTC and HTC laminates.

As is seen in Figure 8, graphite forms a weak interface with the epoxy resin. It is also known that graphite has a higher modulus compared to the epoxy resin and is also harder. Here, we have a situation wherein the two different epoxy resins have hard particles uniformly distributed in them and having a face. It is also known that the HTC epoxy resin is me degree of cure and is hence ductile void or hole generation owing It has been suggested that if a matrix is ductile, verate inhomogeneous deformato separation of a particle from the matrix will geformation in the matrix [17]. This tion in it in the form of shear bands or plast the hard particle, will not make its region, called the modified zone around the much as in the case of RTC resin. presence felt in the more brittle HTC resin as rmins possessing lower cross-link Yee and Pearson [18] found that epoxy density were easily toughened. Based on these grounds, it is argued that

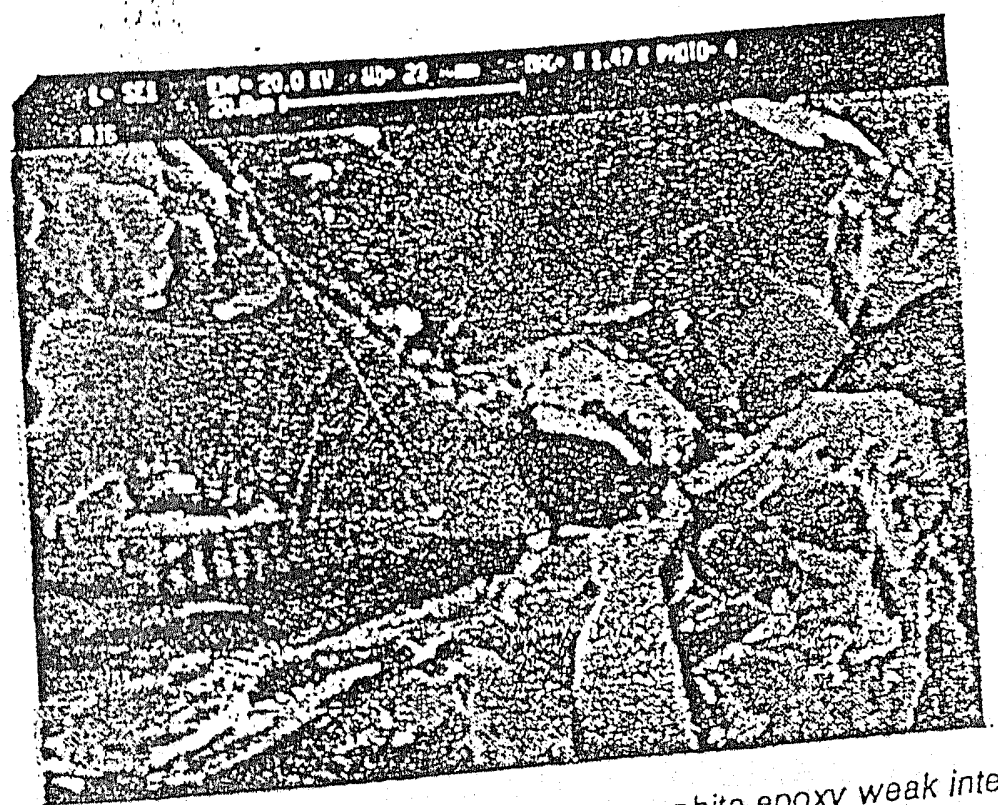

Figure 8. SEM pholograph showing the graphite-epoxy weak interface. 
ing from hard particles is possible only in inherently ductile matrices. In brittle matrices, it is generally believed that the presence of hard particles with inadequate adhesion with the matrix will form voids that will generate a crack due to stress concentration, and a premature failure in the brittle matrix will occur.

However, some workers have suggested toughening of brittle materials by incorporation of hard particles under certain circumstances $[19,20]$. According to them, this is achieved through crack pinning or crack deflection [21] at the hard inclusions. This concept is similar to the strengthening of metals from dislocation pinning. The results obtained in the mechanical tests are a manifestation of these various mechanisms.

ILSS has been recognised to be a matrix dominated phenomenon. The portion of the graph upto 4 wt \% graphite in Figure 1 and Figure 2 clearly demonstrates this view, wherein even very small additions of a hard particle having a weak interface with the matrix bring down the ILSS drastically. It is known that a weak interface site like that of the graphite/epoxy can generate a few cracks but one such site can blunt or deflect only fewer of such cracks. The statistical aspect of such events in the Graphite/epoxy interfacial sites needs investigation. It is also known that only cracks initiated in the favourable direction can propagate as governed by the state of stress. A large fraction of graphite particles are sandwiched between the glass fabric and affinence in the direction of shear, as a result of which more blunting of the cracks or crack detour takes place. The marginal increase in ILSS observed at $6 \mathrm{wt} \%$ graphite may be explained as being the result of increased crack pinning or crack detour occurring at the hard graphite particles. From the foregoing deliberations it may be suggested that ILSS upto 4 wt \% graphite is matrix dominated and above that it is influenced more by the graphite/epoxy interface.

The decrease in the observed values of ILSS for the $5 \mathrm{~mm}$ width specimens in comparison to the $10 \mathrm{~mm}$ width specimens may be explained by studying the fibre

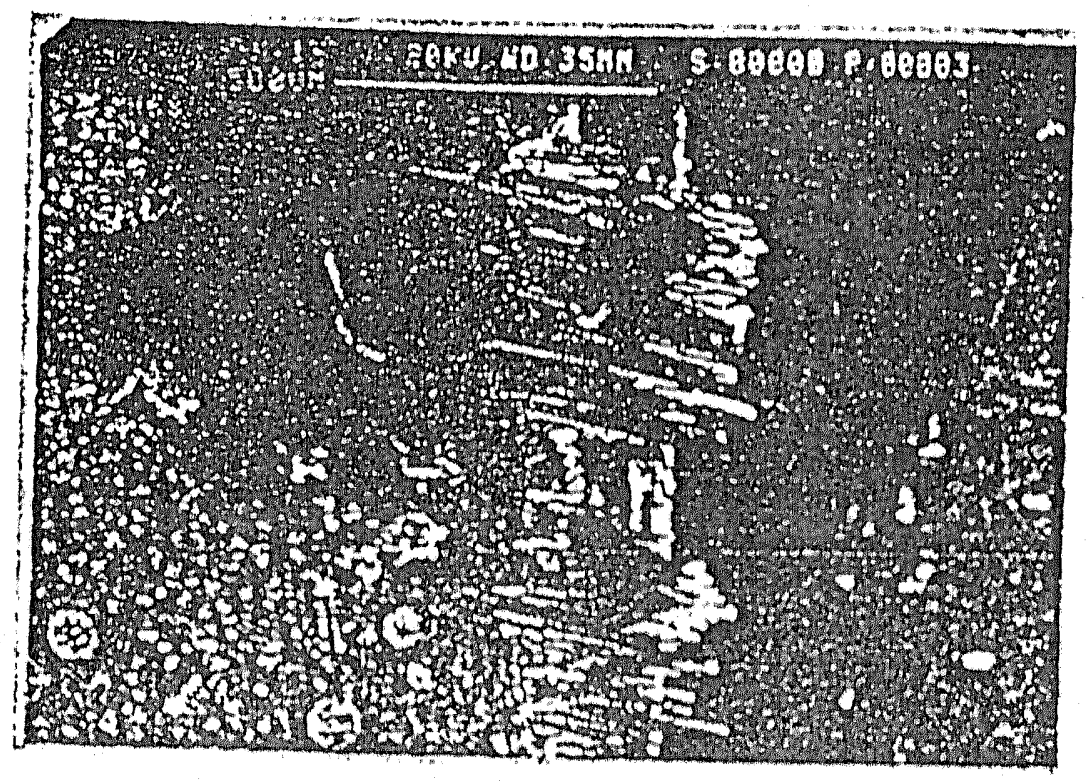

Flgure 9. A typical fibre pull-out on the tension side of an ILSS beam. 
Table 2.

\begin{tabular}{lc}
\hline Specimen & (1) Pullout $\mu \mathrm{m}$ \\
\hline RTC (6 wt. 90 graphite) & 296 \\
$10 \mathrm{~mm}$ widih & 340 \\
$5 \mathrm{~mm}$ width & \\
ATC (unfilled) & 300 \\
$10 \mathrm{~mm}$ width & 340 \\
$5 \mathrm{~mm}$ width & \\
HTC (6 wt.95 graphite) & 450 \\
$10 \mathrm{~mm}$ width & 540 \\
$5 \mathrm{~mm}$ width & \\
HTC (unfilled) & 420 \\
$10 \mathrm{~mm}$ width & 490 \\
$5 \mathrm{~mm}$ width & \\
\hline
\end{tabular}

pull-out from the matrix in SEM and by consideration of the nature of 4 hamess satin weave glass fabric used. Thus examining the fracture feature of the failed speicmens in the SEM, it was found that the extent of fibre pull-out from the matrix for the $5 \mathrm{~mm}$ specimens was greater than those of the $10 \mathrm{~mm}$ width specimens. A typical pull-out is shown in Figure 9. The average pull-out distances are tabulated in Table 2.

The four harness satin glass weave used is shown pictorially in Figure 10. The interlacing points determine the integrity of the fabric. Hence, if two specimens are chosen which differ only in their.widths, the one that has a smaller width will have lesser number of interlacing points along the width. When mechanically tested (as in the determination of ILSS), the fibres in the specimen of smaller

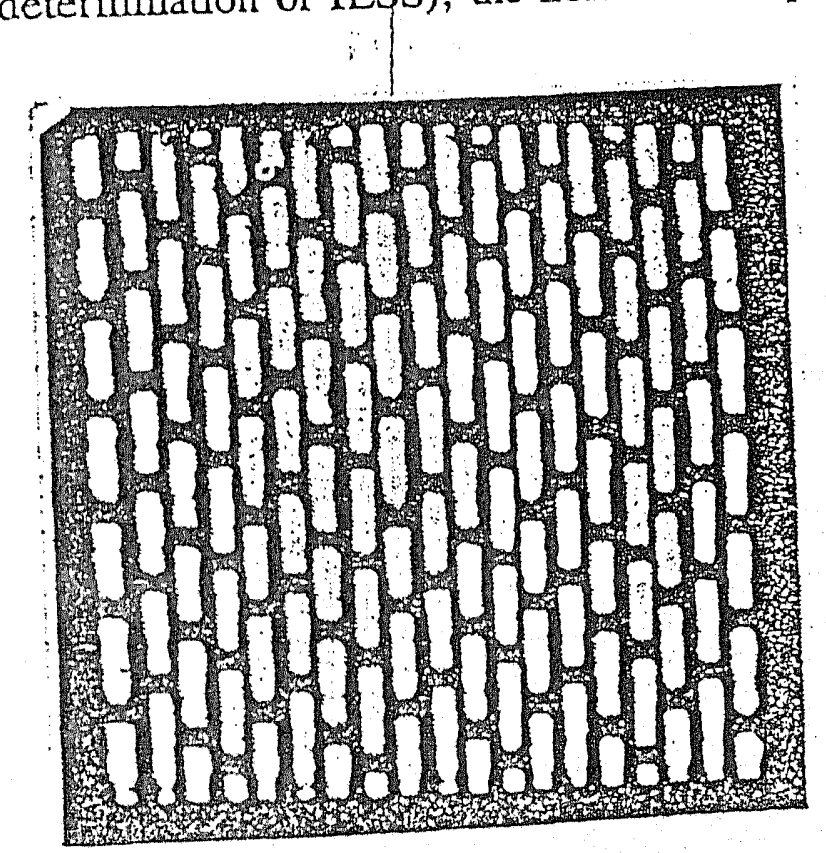

Figure 10. A photograph giving details of four hamess satin weave. 


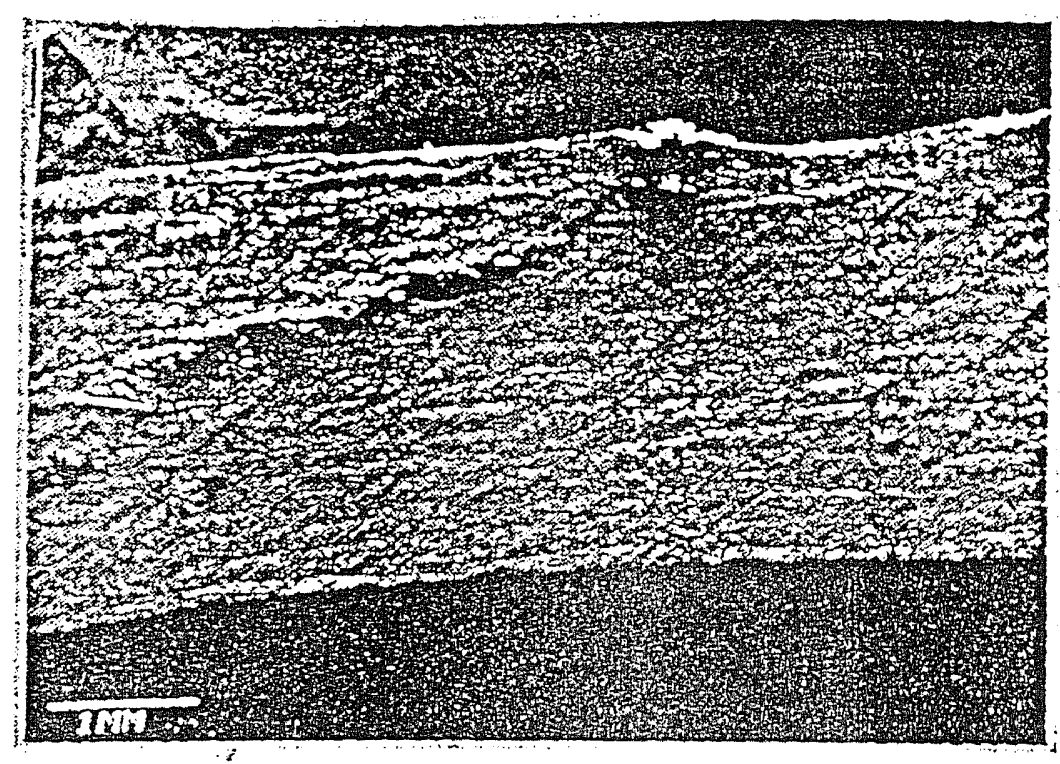

Figure 11. The angle of break of a representative specimen failed in compression.

$$
\begin{aligned}
& 3 \mathrm{~S} \\
& \text { and }
\end{aligned}
$$

width will pull-out from the matrix to a greater extent, due to the weaker transverse reinforcements (interlacing points). which are known to be potential loca-ini tions of load redistribution and shear. The lower values of ILSS for the $5 \mathrm{~mm}$ width specimens on antaverage has been attributed to the ease of fibre pull-out $a n$ from the matrix.

As discussed earlier, many properties seem to be matrix dominated upto" around 4 wt $\%$ graphite and interface influenced for larger additions. Figures 3-7 emphasise the abovesaid aspect. Deflection at shear failure, transverse modulus in tension and the compressive strength and strain exhibit a change in the trend at 4 wt \% graphite. The RTC resin is less brittle, crosslinked to a lesser extent and has a stronger interface with the particulate graphite additions than the HTC resin.

The trends in deflections at failure in the interlaminar mode as shown in Figures 3 and 4 are similar to the strain values in compression tests reported in Figure 7 indicating that the ILSS behaviour is a compression dominated phe-

Table 3.

\begin{tabular}{ccc}
\hline & \multicolumn{2}{c}{$\begin{array}{c}\text { Shear Strength in } \\
\text { Compression }\left(\sigma_{8}\right) \mathrm{MPa}\end{array}$} \\
\cline { 2 - 3 } $\begin{array}{c}\text { Graphite } \\
\text { Wt. Q6 }\end{array}$ & RTC & HTC \\
\hline 0 & 55.2 & 58.9 \\
2 & 50.3 & 52.1 \\
4 & 48.8 & 44.4 \\
6 & 42.5 & 40.7 \\
\hline
\end{tabular}




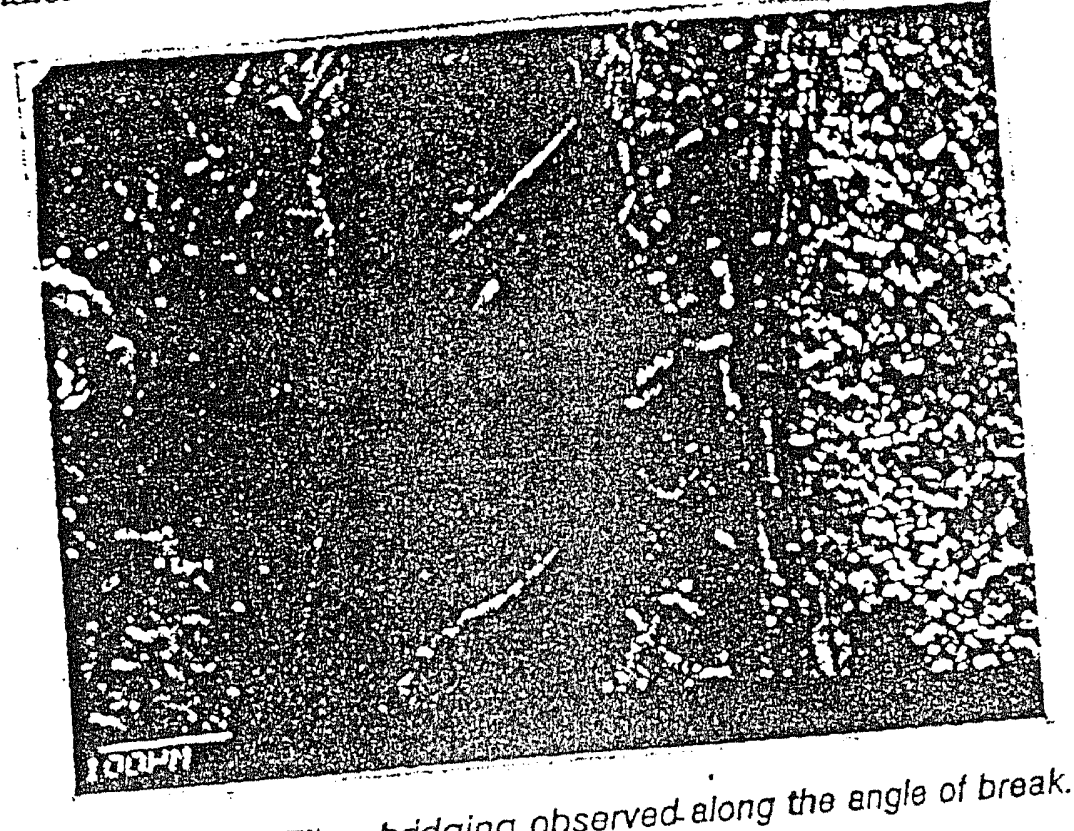

Figure 12. Fibre-bridging observed along the angle of break.

nomenon. It is a well documented fact that the addition of particles whose modulii are higher than the resin increase the santions, beyond which the interface in transverse modulus upto 4 wt \% graphite addion modulus values, thus accounting of the particles with the me rule of mixtures. for the deviation from the rule of mixtures.

The shear strength in compression observed, as shown in a representative SEM section. The average angle of break observed, as each parameter. The calculated fractograph in Figure 11, was determined for each Table 3.

shear strengths in compression are as tabumession is milore than the ILSS. This

It is noticed that the shear strength in comaterial geometry used, test configuration difference perhaps can be traced to the matects in compression where the inplane employed and absence of free edge effects in cause significant fibre bridging loading configuration enables an angled break to chition the shear strength in comas shown in Figure 12. At about $6 \%$ graph of the unfilled specimens.

pression becomes comparable to the ILss of the

\section{CONCLUSIONS}

From the results of this study the following important conclusions emerge.

1. The initial decrease in the ILSS which is observed upto $4 \mathrm{wt} \%$ graphite in all the cases has been attributed to the formation of more weaker in initiation (graphite/epoxy) within the matrix thereby leas, the ILSS improves due to the events. But as the graphite addition is increased crack detour which occur at the increased occurrence of crack pinning and be said that the ILSS test results hard graphite particles. In this sense, it mated mechanical behaviour to an intersuggest a transition from matrix dom 4 wt graphite additions.

were, on an average, less than those The ILSS of the $5 \mathrm{~mm}$ width specimens were, 
of the $10 \mathrm{~mm}$ specimens because of the role played by the transverse interlac. ing points on the pull-out characteristics of the axial fibres. It was also seen that the addition of a particulate filler like graphite did not have any influence on the "width effect" noticed in the deflection at failure for the above mentioned specimens.

3. The transverse modulus of both the RTC and HTC laminates show an initial increase and then decrease appreciably in the case of Room Temperature Cured resin but only marginally in the case of High Temperature Cured resin. Above $4 \mathrm{wt} \%$ graphite, the influence of the interfaces supercede the effect of the rule of mixtures.

4. The compression strength and strain of the RTC specimen shows an increase upto 4 wt \% graphite owing to the increased plasticity of the resin surrounding the graphite particles. The compression strength and strain of the HTC samples show an identical behaviour as in the case of ILSS. For the test condition and material geometry employed the shear stress in compression is seen to be more than the ILSS.

\section{ACKNOWLEDGEMENTS}

The authors thank the Chaiman-Dept-mof Metallurgy for theitencouragement and facilities extended. The support and encouragement extendedbry The Head, Materials Science Division and The Director, National Aerospace Laboratories are greatly appreciated.

\section{REFERENCES}

1. Lee, H. and K. Neville. 1967. Handbook of Epoxy Resins, New York, NY: McGraw-Hill, pp. 14- 17 .

2. Lange, F. F. and K. C. Radford. 1971. I. Mater. Sci., p. 1197.

3. Radford, K. C. 1971. J. Marer. Sci., p. 1286.

4. Padmanabhan, K. and Kishore. 1990. Bull. Mater. Sci., 13:245-253.

5. Subramanian, C., P. Asaithambi and Kishore. 1986. Jl. of Reinforced Plasrics and Composites, 5:200-208.

6. Chai, M. 1990. Intl. Il. of Fracture, 43:117-131.

7. ASTM STP D 2344-84. 1989. Annual Book of ASTM Standards, Vol. 15.03, Philadelphia.

8. ASTM STP D3410-87. Idem.

9. ASTM STP D3039-76. Idem.

10. Chai, H. 1988. Intl. J. of Fracrure, 37:137-159.

11. Sidey, G. R. and F. J. Bradshaw. 1971. "Carbon Fibres Their Composites and Applications," Proc. Inst. Canf. of the Plastics Inst., London, pp. 208-213.

12. Guo, Y., D. Post and B. Han. 1992. Jl. Comp. Mater., 26:301.

13. Hull, D. 1981. An Inrraducrion ro Composite Marerials, Cambridge Univ. Press, p. 159.

14. Ewin, P. D. and A. C. Han. 1973. Royal Aircraft Establishment Tech. Report, 73057.

15. Miller, A. K. and D. F. Adams. 1978. "Advanced Composite Materials-Environmental Effets," J. R. Vinson, od., 15TM STP 658.

16. Padmanabhan, K. and Kishore. 1993. "Fibre-Matrix Interfacial Failure Sequences in Translaminar Flexure of Glass-Epoxy Composites," Jl. Mater. Sci., in press. 
17. Amar, C. G. and Mai, Y.W. 1988. Comp. Sci. Tech., 31:179-223.

18. Yee, A. F. and R. A. Pearson. 1986. Jl. Mater. Sci., 21:2462-2474. (Also see NA.SA.CR 3718, 1983).

19. Evans A. G. 1973. Phil. Mag., 26:1327.

20. Spanoudakis, J. and R. J. Young. 1984. Jl. Mater. Sci, 19:473.

21. Raghava, K. R. 1988. J1. of Poly. Sci. Part B Polymer Physics, 26:65. 